\title{
Cell death in amastigote forms of Leishmania amazonensis induced by parthenolide
}

\author{
Tatiana Shioji Tiuman ${ }^{1}$, Tânia Ueda-Nakamura ${ }^{1}$, Antonio Alonso ${ }^{2}$ and Celso Vataru Nakamura ${ }^{1 *}$
}

\begin{abstract}
Background: Leishmania amazonensis infection results in diverse clinical manifestations: cutaneous, mucocutaneous or visceral leishmaniasis. The arsenal of drugs available for treating Leishmania infections is limited. Therefore, new, effective, and less toxic leishmaniasis treatments are still needed. We verified cell death in amastigote forms of Leishmania amazonensis induced by the sesquiterpene lactone parthenolide.

Results: The tested compound was able to concentration-dependently affect axenic and intracellular amastigotes, with $I_{50}$ values of $1.3 \mu \mathrm{M}$ and $2.9 \mu \mathrm{M}$, respectively after $72 \mathrm{~h}$ incubation. No genotoxic effects were observed in a micronucleus test in mice. Parthenolide induced morphological and ultrastructural changes in axenic amastigotes, including a loss of membrane integrity, swelling of the mitochondrion, cytoplasmic vacuoles, and intense exocytic activity in the region of the flagellar pocket. These results led us to investigate the occurrence of autophagic vacuoles with monodansylcadaverine and the integrity of the plasma membrane and mitochondrial membrane potential using flow cytometry. In all of the tests, parthenolide had positive results.

Conclusions: Our results indicate that the antileishmanial action of parthenolide is associated with autophagic vacuole appearance, a reduction of fluidity, a loss of membrane integrity, and mitochondrial dysfunction. Considering the limited repertoire of existing antileishmanial compounds, the products derived from medicinal plants has been one the greatest advances to help develop new chemotherapeutic approaches.
\end{abstract}

Keywords: Leishmania amazonensis, Amastigotes, Parthenolide, Cell death, Autophagy

\section{Background}

Leishmaniasis is associated with high morbidity but low mortality. It is a poverty-related disease and has become a serious impediment to socioeconomic development. The true burden of this illness remains unclear because the notification of the disease is compulsory in only 32 of the 88 affected countries, and most of the affected people live in remote areas. Additionally, the disfiguring scars caused by Leishmania keep patients hidden. An estimated 1.5 million new cases of cutaneous leishmaniasis and 500,000 cases of visceral leishmaniasis occur annually, with approximately 12 million people currently infected [1]. Moreover, cases of Leishmania and human immunodeficiency virus co-infection are becoming more frequent $[2,3]$.

Leishmania (Leishmania) amazonensis infection results in diverse clinical manifestations, ranging from cutaneous

\footnotetext{
* Correspondence: cvnakamura@uem.br

'Programa de Pós-Graduação em Ciências Farmacêuticas, Universidade Estadual de Maringá, Av. Colombo 5790, 87020-900 Maringá, Paraná, Brazil Full list of author information is available at the end of the article
}

to mucocutaneous or visceral involvement [4]. This is attributable to the genetic diversity of L. amazonensis strains, and this divergence extends to variations of chromosome size [5].

The arsenal of drugs available for treating Leishmania infections is limited. The basic treatment consists of administering pentavalent antimonial compounds [6]. However, the choice of medication depends on the species involved and type of clinical manifestation [7]. The usefulness of antileishmanial drugs has been limited by their toxicity, and treatment failure is often attributable to drug resistance [8]. To solve this problem, developing less toxic drugs and discovering cellular and molecular markers in parasites to identify the phenotype of chemoresistance against leishmanicidal drugs are necessary $[8,9]$. These problems led to the development of additional antileishmanial drugs. Some drug-delivery systems, plants, and synthetic compounds are being developed as effective treatments for the disease [7]. 
Previous studies demonstrated the in vitro activity of parthenolide, a sesquiterpene lactone purified from Tanacetum parthenium, against promastigotes and intracellular amastigotes (inside J774G8 macrophages) of L. amazonensis [10]. Moreover, significant alterations in promastigote forms were demonstrated by light microscopy and scanning and transmission electron microscopy [11].

We evaluated the activity of parthenolide against $L$. amazonensis axenic amastigotes and demonstrated a possible mechanism of action of this compound in this life stage of the parasite.

\section{Results}

\section{Antileishmanial assays}

The addition of $4.0 \mu \mathrm{M}$ parthenolide to the culture of axenic amastigotes induced growth arrest and partial cell lysis after $48 \mathrm{~h}$ (i.e., growth inhibition up to 90\%). When the cells were treated with $2.0 \mu \mathrm{M}$ parthenolide, the percentage of growth inhibition was approximately $70 \%$. Parthenolide had an $\mathrm{IC}_{50}$ of $1.3 \mu \mathrm{M}$ and $\mathrm{IC}_{90}$ of $3.3 \mu \mathrm{M}$ after $72 \mathrm{~h}$ incubation (Figure $1 \mathrm{~A}$ ).
A concentration of 1.0 or $0.5 \mu \mathrm{M}$ of the reference drug amphotericin B inhibited more than $93 \%$ of L. amazonensis amastigote cell growth. This drug had an $\mathrm{IC}_{50}$ and $\mathrm{IC}_{90}$ of $0.22 \mu \mathrm{M}$ and $0.45 \mu \mathrm{M}$, respectively, after culturing for $72 \mathrm{~h}$ (Figure 1B).

Parthenolide also inhibited the growth of intracellular amastigotes in mouse resident peritoneal macrophages after $24 \mathrm{~h}$ incubation. Treatment with 4.0, 3.2, 2.4, and 1.6 $\mu \mathrm{M}$ parthenolide reduced the proliferation of parasites into macrophages (survival index) by $82.5,59.4,37.3$, and $6.1 \%$, respectively, compared with the control. The survival index indicated that parthenolide inhibited the intracellular viability and multiplication of Leishmania in infected murine macrophages and showed 50\% inhibition of cell survival at a concentration of $2.9 \mu \mathrm{M}$ (Figure 2).

Previous studies showed that when J774G8 murine macrophages were treated with parthenolide, the $50 \%$ cytotoxic concentration $\left(\mathrm{CC}_{50}\right)$ was $56.4 \mu \mathrm{M}[10]$. By comparing the toxicity for J774G8 macrophages and activity against intracellular amastigotes, obtaining the selectivity index ratio is possible $\left(\mathrm{CC}_{50}\right.$ for $\mathrm{J774G8}$ cells/ $\mathrm{IC}_{50}$ for protozoa). In the
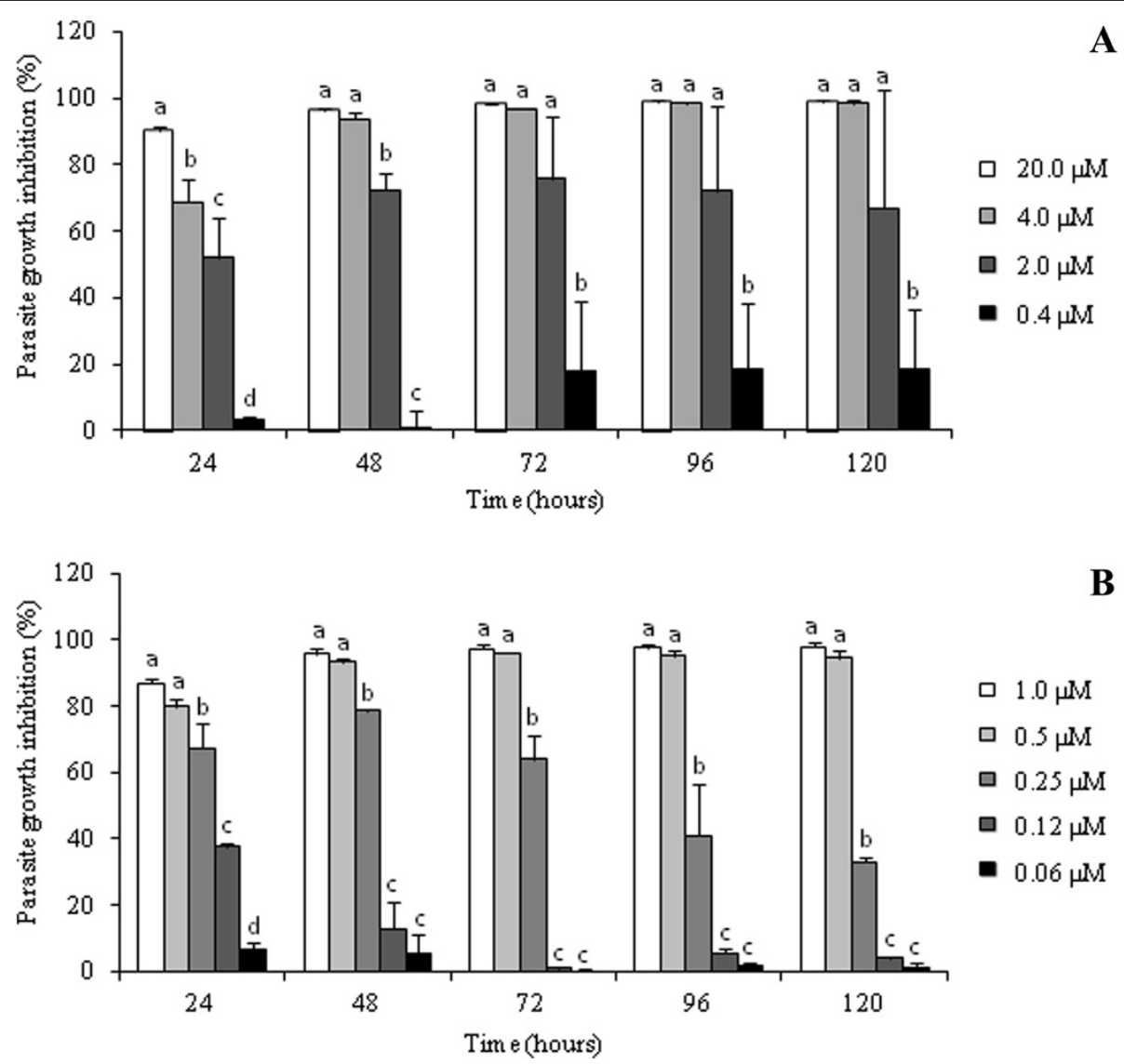

Figure 1 Effects of parthenolide (A) and amphotericin B (B) on the growth of L. amazonensis axenic amastigotes. After treatment with different concentrations of the drugs, parasites were counted, and the percentage of parasite growth inhibition was determined daily for $120 \mathrm{~h}$. The data indicate the average of the two independent experiments performed twice. Statistical analysis: the data of each incubation period were compared statistically at $p<0.05$. Bars that are not indicated with letters in common are statistically different. 


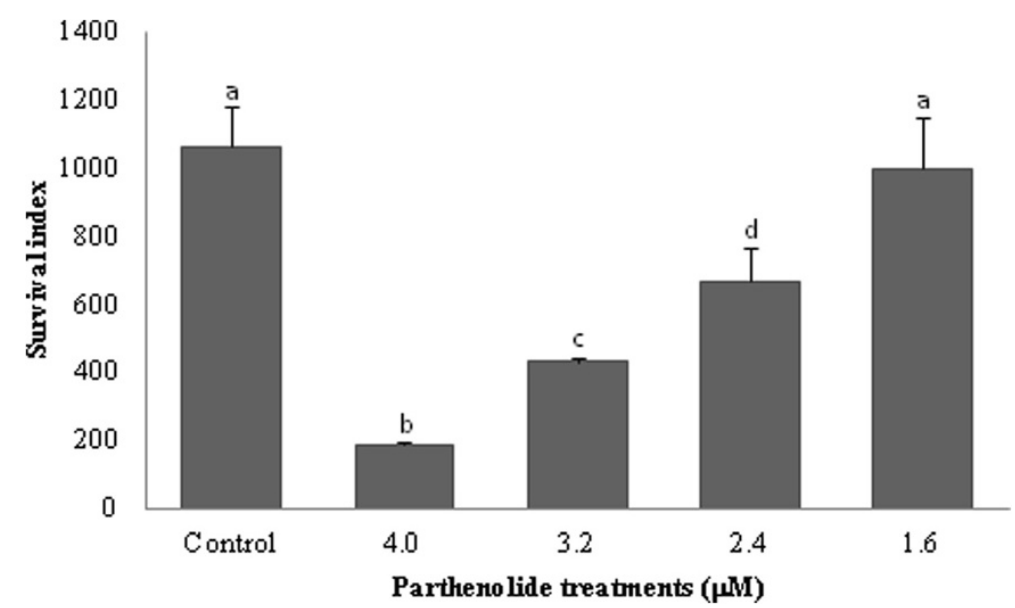

Figure 2 Effect of parthenolide on amastigotes of L. amazonensis in mouse resident peritoneal macrophages. Peritoneal macrophage cells were infected with promastigote forms, and then intracellular amastigotes were treated with different concentrations of parthenolide. After $24 \mathrm{~h}$ treatment, the survival index was calculated by multiplying the percentage of macrophages with internalized parasites and mean number of internalized parasites per macrophage. The results shown are from one representative experiment of two independent experiments performed in duplicate. The data were compared statistically at $p<0.05$. Bars that are not indicated with letters in common are statistically different.

present study, parthenolide had an $\mathrm{IC}_{50}$ of $2.9 \mu \mathrm{M}$, presenting a selectivity index ratio of 19.4 (i.e., the compound is 19.4-times more selective against parasites than host cells).

\section{Mutagenicity evaluation}

The results of the in vivo bone marrow micronucleus test in rats are shown in Table 1. Parthenolide did not induce genotoxic effects at a concentration of $3.75 \mathrm{mg} / \mathrm{kg}$ body weight, with no significant increase in the frequency of MNPCE $(10.0 \pm 1.6)$ compared with the vehicle control group $(7.0 \pm 1.8)$. In contrast, a significant increase in the frequency of MNPCE was observed in the positive control group (cyclophosphamide; $27.0 \pm 4.0$ ). In the present study, no clinical signs of toxicity were observed in treated animals. However, further studies should be performed with higher concentrations of parthenolide to exclude the possibility of genotoxicity.

\section{Scanning and transmission electron microscopy}

To determine the morphological and ultrastructural changes in L. amazonensis axenic amastigotes induced by parthenolide, the cells were treated with the $\mathrm{IC}_{50}(1.3 \mu \mathrm{M})$

Table 1 Micronucleated polychromatic erythrocyte (MNPCE) score in 2,000 reticulocytes from bone marrow of mice

\begin{tabular}{cc}
\hline Treatment & MNPCE (mean \pm SD) \\
\hline Vehicle & $7.0 \pm 1.8$ \\
Cyclophosphamide & $27.0 \pm 4.0^{\mathrm{b}}$ \\
Parthenolide & $10.0 \pm 1.6^{\mathrm{a}}$ \\
\hline
\end{tabular}

Findings after $24 \mathrm{~h}$ oral treatment with vehicle (negative control), cyclophosphamide (positive control), and parthenolide.

${ }^{a}$ No significant difference compared with negative control and significant difference compared with positive control $(p<0.05)$.

${ }^{\mathrm{b}}$ Significant difference compared with negative control $(p<0.05)$. of the compound. Untreated controls showed no morphological (Figure 3A) or ultrastructural (Figure 3D) differences. Similarly, cells incubated with 0.05\% DMSO (i.e., the same concentration used in the final solutions of parthenolide) remained unaltered (data not shown). When treated with parthenolide, changes in form were visualized by scanning electron microscopy (Figure $3 \mathrm{~B}$ and $\mathrm{C}$ ). Transmission electron microscopy showed a loss of membrane integrity associated with amphotericin B exposure at the $\mathrm{IC}_{50}$ concentration (Figure 3E). Parthenolide caused intense swelling of the mitochondrion (Figure 3F) and cytoplasmic blebbing (Figure 3G). Finally, the ultrastructural analysis showed that amastigotes treated with parthenolide formed multiple cytoplasmic vacuoles (Figure 3H), and intense exocytic activity was observed in the region of the flagellar pocket, appearing as concentric membranes within the pocket (Figure 3I).

\section{Labeling of autophagic vacuoles with monodansylcadaverine}

We studied the incorporation of monodancylcadaverine (MDC) in cells in which autophagy was stimulated by parthenolide. Axenic amastigotes treated with the $\mathrm{IC}_{50}$ (Figure $4 \mathrm{~B}$ ) or $\mathrm{IC}_{90}$ (Figure $4 \mathrm{C}$ ) of parthenolide showed an increase in the number of vesicles, indicating that the compound induced the formation of MDC-labeled vacuoles in the cytoplasm. MDC-positive cells were visualized in treated cells but not in control cells (Figure 4A) or amphotericin-treated cells (data not shown). These results show that parthenolide treatment, unlike amphotericin $\mathrm{B}$, led to the formation of autophagic vacuoles in L. amazonensis amastigotes. 


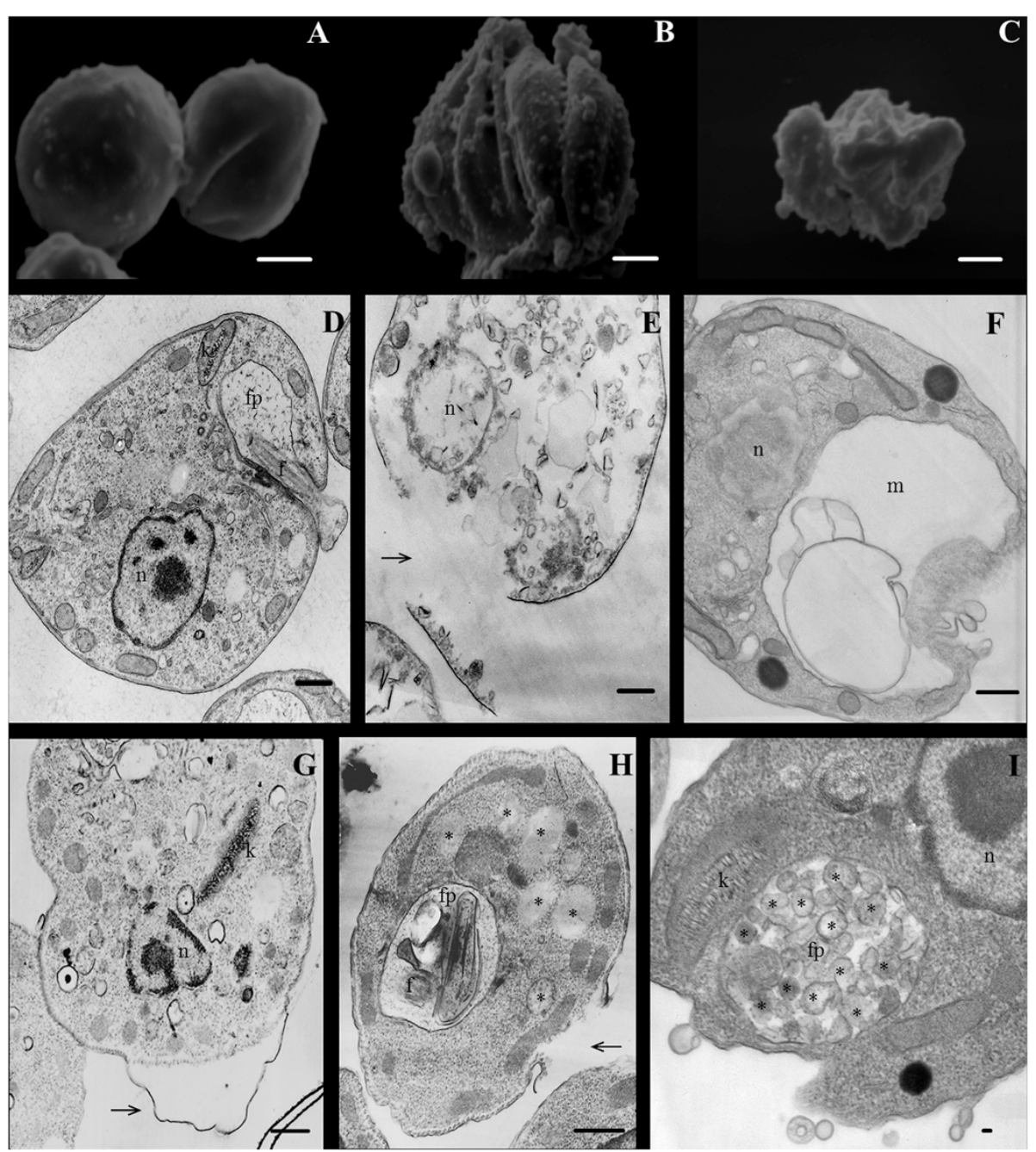

Figure 3 Scanning $(A-C)$ and transmission (D-I) electron microscopy of axenic amastigotes of $L$. amazonensis treated with parthenolide. Amastigotes were incubated for $72 \mathrm{~h}$ in the absence $\mathbf{A}$ and $\mathbf{D})$ or presence $\mathbf{( B}, \mathbf{C}, \mathbf{F}-\mathbf{I})$ of the $\mathrm{IC}_{50}(1.3 \mu \mathrm{M})$ of parthenolide. For transmission electron microscopy, the treatment of amastigotes was also accomplished using the $I_{50}$ of amphotericin $B$ as a reference drug that acts on the cytoplasmic membrane (E). The arrows indicate plasma membrane blebs or loss of membrane integrity, and the asterisks indicate vesicles located in the cytoplasm or flagellar pocket. $\mathrm{n}$, nucleus; f, flagellum; fp, flagellar pocket; m, mitochondrion; $\mathrm{k}$, kinetoplast. Scale bars $=1 \mu \mathrm{m}$.
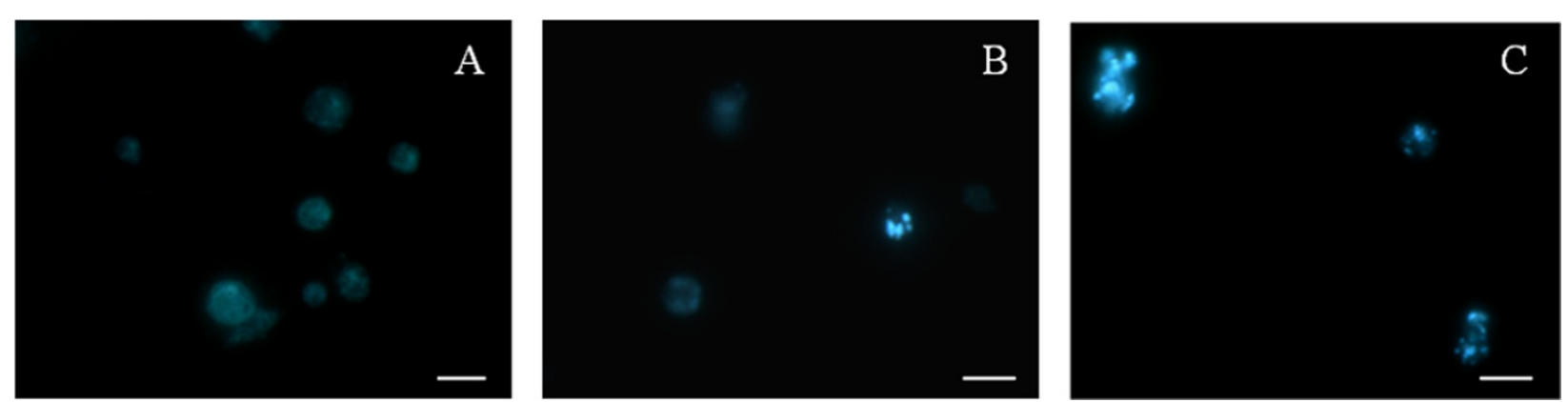

Figure 4 Monodansylcadaverine (MDC)-labeled vesicles in axenic amastigotes of $L$. amazonensis induced by parthenolide treatment. Amastigotes were incubated for $72 \mathrm{~h}$ in Schneider medium (control cells) $(\mathbf{A})$ or in the presence of the $I C_{50}$ (B) or I $\mathbf{C}_{90}$ (C) of parthenolide. The data are representative of at least three independent experiments. Scale bars $=5 \mu \mathrm{m}$. 
Flow cytometric measurement of amastigote culture

Live L. amazonensis cells were incubated with propidium iodide and rhodamine 123, and fluorescence was measured by flow cytometry. The gated percentage of propidium iodide-stained amastigotes after treatment with amphotericin B (positive control) was $71.4 \%$, much higher than untreated parasites (negative control) that presented 6.0\% (Figure 5A). When the cells were treated with 20 and $40 \mu \mathrm{M}$ parthenolide, the percentages of labeled amastigotes were $34.2 \%$ and $56.2 \%$, respectively (Figure $5 \mathrm{~B}$ ), possibly indicating a considerable increase in plasma membrane permeability. To prove that Leishmania cells functionally respond to the pharmacological alteration of $\Delta \Psi_{\mathrm{m}}$, amastigotes were treated with the protonophore carbonyl cyanide $m$-chlorophenylhydrazone (CCCP), which has been shown to interfere with mitochondrial membrane potential in various cell types [12]. The results showed that $82.5 \%$ of the amastigotes without treatment (negative control) presented a maximal increase in fluorescence, and with $200 \mu \mathrm{M}$ CCCP, 46.7\% showed fluorescence, indicating a loss of $\Delta \Psi_{\mathrm{m}}$ (Figure $5 \mathrm{C}$ ). We next observed $\Delta \Psi_{\mathrm{m}}$ reductions of $68.4 \%$ and $56.1 \%$ when the amastigotes were treated with 20 and $40 \mu \mathrm{M}$ parthenolide, respectively, suggesting that this compound interferes with the mitochondrial membrane potential leading to alteration of ATP generation and in consequence cell damage takes place.

\section{EPR spectra of spin-labeled Leishmania}

The experimental and best-fit EPR spectra of spin-label 5DSA structured in the plasma membrane of Leishmania are shown in Figure 6. These EPR spectra are typical for cellular membranes that contain an appreciable amount of integral proteins. Treatment with parthenolide increased two EPR parameters, the outer hyperfine splitting, $2 \mathrm{~A}_{/ /}$, and rotational correlation time, $\tau_{C}$, indicating a significant reduction of membrane lipid dynamics. $2 \mathrm{~A}_{/ /}$is a practice parameter measured directly in EPR spectra that has been widely used to monitor membrane fluidity, although in principle it is a static parameter associated with the orientation distribution of the spin labels in the membrane. The theoretical EPR spectrum of spin-label 5-DSA in the plasma membrane of Leishmania was best fitted using a model of two spectral components. This indicates that the membrane has two populations of spin labels of distinct mobility. The EPR spectra of spin labels in lipid bilayers are well known to contain proteins sometimes

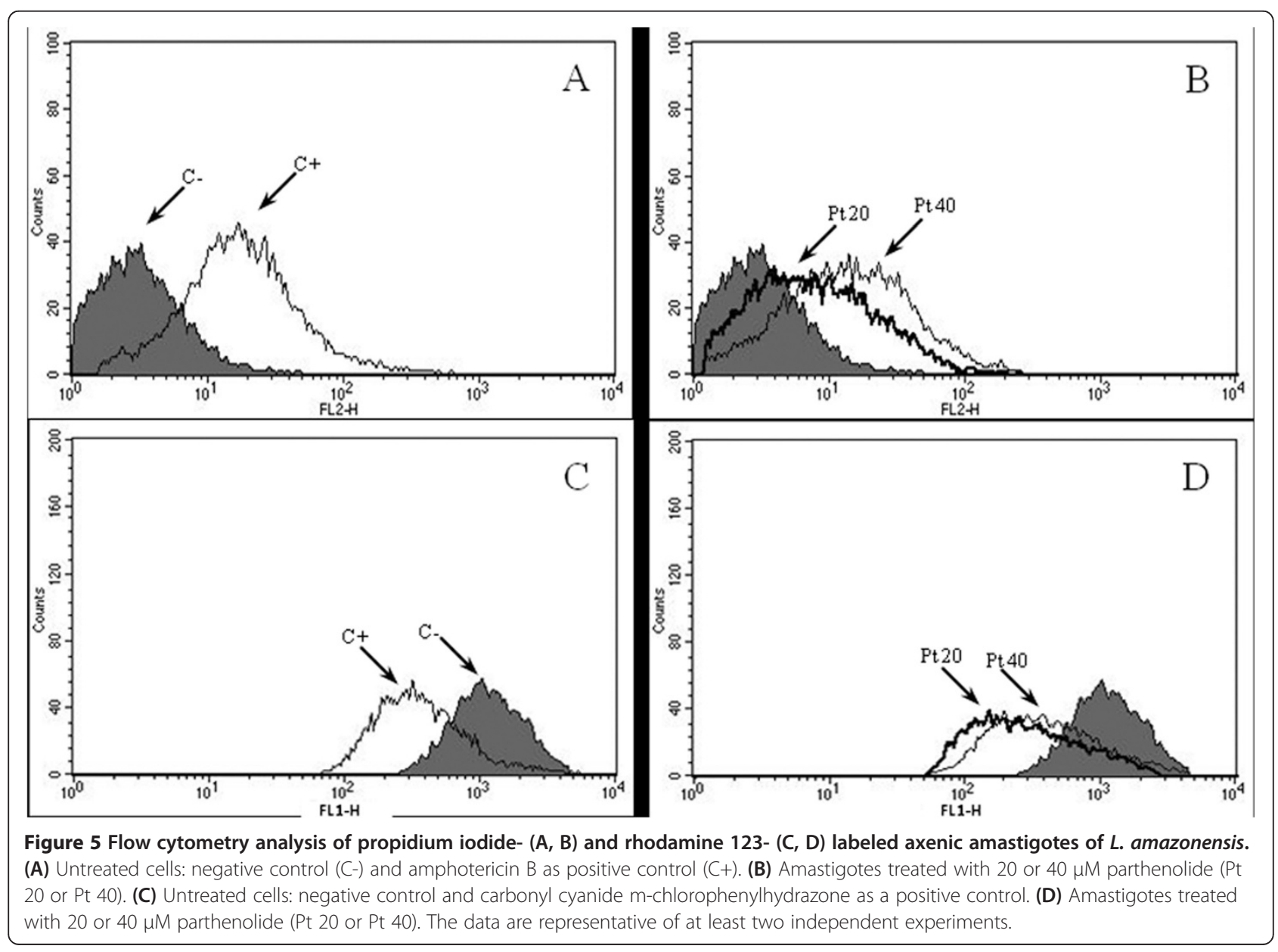




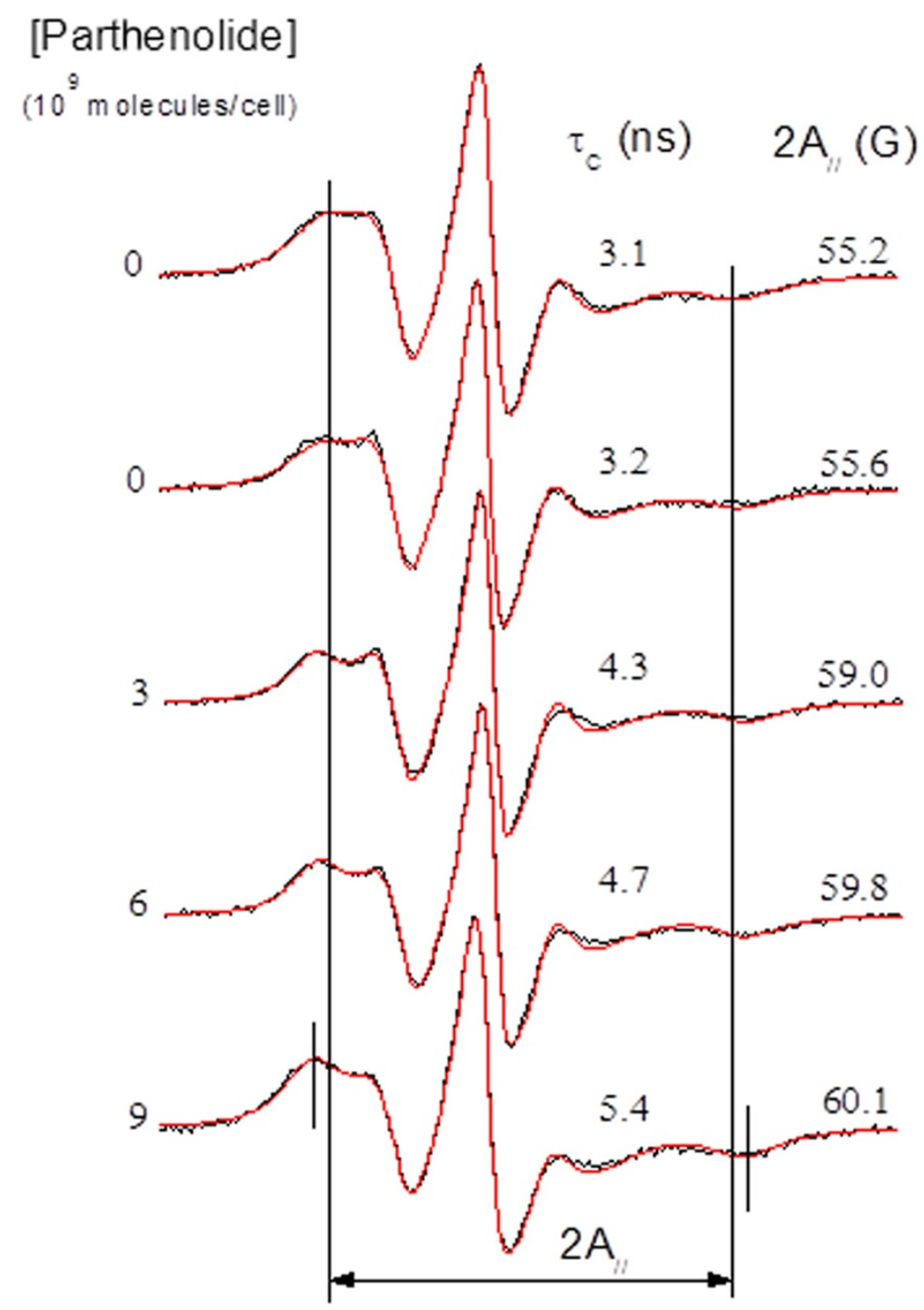

Figure 6 Experimental EPR spectra (black line) and theoretical fits (red line) of spin-label 5-DSA in Leishmania membrane. The experiment was conducted at $26^{\circ} \mathrm{C}$ for samples untreated and treated with parthenolide at the indicated concentrations. EPR spectra were simulated with the NLLS fitting program, and the values of the parameter rotational correlation time, $\tau_{C}$, obtained from the fit for each spectrum are indicated on a nanosecond scale. The EPR parameter 2A, is the separation in magnetic-field units between the first and last resonance lines of the spectrum. The vertical lines indicate the $2 \mathrm{~A}$, for the control samples, and the smaller vertical lines illustrate the increase in $2 \mathrm{~A}$, for the sample treated with $9 \times 10^{9}$ molecules/cell. The measured $2 A_{/}$, values and $\tau_{C}$ values indicate that the presence of parthenolide significantly reduced lipid fluidity. The estimated experimental errors for the $2 \mathrm{~A}$ //and $\tau_{c}$ parameters are $0.5 \mathrm{G}$ and $1.0 \mathrm{~ns}$, respectively.

composed of two spectral components. The more restricted component is associated with boundary lipids where the spin labels surround the hydrophobic regions of proteins, whereas the more mobile component arises from the spin labels located in the bulk bilayer phase, away from the protein [13]. The fitting program provides the $\tau_{c}$ and population of each component. Thus, the mean of the rotational correlation time was calculated as $\tau_{c}=N_{1}{ }^{*} \tau_{c 1}+N_{2}{ }^{*} \tau_{c 2}$, in which $N_{1}$ and $N_{2}$ are the fractions of the population in components 1 and 2 , respectively, and $\tau_{c 1}$ and $\tau_{c 2}$ are the corresponding rotational time correlations.

\section{Discussion}

For many years, parasites of the genus Leishmania have displayed extraordinary plasticity to face modifications in their environment [14]. The expansion of risk factors related to environmental changes and man-made transformations are making leishmaniasis a growing public health concern in many countries worldwide [15]. Leishmaniasis urgently needs novel drugs with improved features, and many compounds primarily derived from plants are promising leads for the development of novel chemotherapeutics [16].

The development of axenic cultures of amastigotes of Leishmania species yielded new opportunities to investigate 
the antileishmanial activities of new compounds directly at the mammalian stage of the parasite [17]. Assays that use intracellular amastigote cell cultures are relevant because this life cycle stage of the parasite is important to its pathogenicity, and data obtained exclusively from promastigote cell lines are insufficient [16]. Therefore, in the present study, we determined the leishmanicidal activity of parthenolide, which is naturally occurring, in both axenic and intracellular amastigotes.

To discover better leishmanicidal compounds, the isolation and purification of the active ingredients of medicinal plants are gaining attention [18]. Many new natural product groups, such as terpenes, have exhibited antiprotozoal potential and attracted renewed interest with surprising efficacy and selectivity [19].

Parthenolide is a lipophilic hydrocarbon compound formed by units of isoprene. The accumulation of lipophilic compounds in the cytoplasmic membrane and membrane constituents of microorganisms has considerable effects on the loss of cellular integrity and inhibition of respiratory cellular activity in mitochondria [20]. This interaction with cell membranes eventually leads to cell death. In our research, parthenolide had antileishmanial effects against axenic and intracellular amastigotes of $L$. amazonensis presenting $\mathrm{IC}_{50}$ of 1.3 after $72 \mathrm{~h}$ growth and $2.9 \mu \mathrm{M}$ after $24 \mathrm{~h}$ growth, respectively. The differences in $\mathrm{IC}_{50}$ values can be explained because the experiments with axenic amastigotes are directed against the relevant stage of the parasite whereas the use of intracellular amastigotes will give essential information on the capacity of the drugs to target intracellular organisms. The role played by the macrophages on drug-mediated toxicity may be important. Their presence may limit the availability of the compounds under evaluation [21,22].

The toxicity for J774G8 macrophages and the activity against intracellular amastigotes were compared by using the selectivity index ratio $\left(\mathrm{CC}_{50}\right.$ for J774G8 cells/ $\mathrm{IC}_{50}$ for protozoa) [10]. The parthenolide was more selective against the intracellular amastigotes than the mammalian cells, with a selectivity index ratio of 19.4. It is generally considered that biological efficacy is not due to in vitro cytotoxicity when this index is $\geq 10$ [23,24].

The low toxicity against mammalian cells is an important criterion in the search for active compounds with antiprotozoal activity. For this purpose, the genotoxicity of parthenolide in a mouse model was determined using a micronucleus test and cyclophosphamide as the positive control because it is a known genotoxin [25]. Micronuclei are masses of cytoplasmic chromatin that appear outside the main nucleus as a result of chromosomal damage or damage to the mitotic apparatus in the erythroblasts of the test species, and they can be used as an indicator of the effects of agents that cause DNA damage [26]. In mice, micronuclei in mature erythrocytes in peripheral blood live approximately 1 month, providing a measure of average chromosomal damage [27]. Our results showed no differences in the frequency of MNPCE compared with the negative control, demonstrating no toxic effects on bone marrow at the dose tested (3.75 mg/kg body weight).

Electron microscopic studies revealed extensive cytoplasmic vacuolization, leading to the examination of the possibility that parthenolide induces autophagic cell death. Autophagy cell death is a process that is thought to occur in all eukaryotes and is characterized by an accumulation of autophagic vacuoles. This mechanism occurs for energy production for survival when cells recycle their cytoplasmic contents during periods of environmental stress or certain stages of development. A double-membrane vesicle called the autophagosome forms in the cytosol, engulfing organelles and bulk cytoplasm. Subsequently, these vesicles fuse with lysosomes, where their contents are degraded and recycled [28]. One of the most frequently used methods to examine autophagy is staining with acidotropic dyes [29], and MDC is considered an autofluorescent compound and specific marker for autophagic vacuoles [30]. MDC staining is only obtained when the compartments into which it loads are acidic. Neutralization of these compartments leads to a swift loss of MDC staining or lack of MDC uptake [31]. Therefore, we suggest that the vacuoles that were observed under a transmission electron microscope are autophagosomes. Another study used MDC as a marker to analyze the molecular level of the machinery involved in the autophagic process [32] and was also used to demonstrate that antimicrobial peptides induce autophagic cell death in $L$. donovani [33].

Amphotericin B was used as a positive control in some of our experiments because this polyene antibiotic forms aqueous and nonaqueous pores in membranes, which is the basis of leishmanicidal action [34]. Using transmission electron microscopy, we could see the loss of membrane integrity induced by this antimicrobial agent. Similarly, alterations in the cytoplasmic membrane, including membrane blebbing and disruption, could be visualized in axenic amastigotes treated with parthenolide. Studies have shown that a flow cytometric membrane potential assay can be used as a reliable tool for studying the interactions between amphotericin $\mathrm{B}$ and the Leishmania membrane [35]. Alterations in membrane permeability are detected by propidium iodide nucleic acid stain that selectively passes through plasma membranes and bind to DNA, emitting high fluorescence when excited by an argon ion laser [36]. Since its introduction, the propidium iodide flow cytometric assay has also been widely used as a quantitative measure of cell apoptosis. During apoptosis, DNA fragmentation occurs, with a subsequent loss of cellular DNA content [37]. 
Terpenoic compounds can produce major changes in the cellular and mitochondrial membrane structures of different pathogenic agents, modifying their permeability and integrity [20]. Ultrastructural findings also revealed mitochondrial damage induced by parthenolide. We used flow cytometry analysis to determine whether the compound interferes with the mitochondrial membrane potential of the amastigotes. The flow cytometry results showed that transmembrane potential decreased, reflected by a reduction of rhodamine 123 fluorescence. Rhodamine 123 is a fluorescent cationic stain for mitochondria in living cells and is subsequently washed out of the cells once the mitochondrion's membrane potential is lost [38]. The present results indicated an increase in proton permeability through the internal mitochondrial membrane, inhibition of electron transport, or decrease in mitochondrial substrate transport/oxidation, which would impair proton pumping by mitochondrial complexes and reduce adenosine triphosphate synthesis, resulting in parasite cell death [39]. CCCP was used as positive control because it is an uncoupler of oxidative phosphorylation and reduces mitochondrial membrane potential by directly attacking the proton gradient across the inner mitochondrial membrane $[12,40]$. Amastigotes treated with parthenolide presented severe plasma membrane and mitochondrial damage, suggesting an autophagic process [39].

Treatment with parthenolide induced shedding of the membranes into the flagellar pocket, appearing as concentric membranes and suggesting intense exocytic activity because this site is where endocytosis and exocytosis occur in trypanosomatids. Treatment of promastigote forms of L. amazonensis with edelfosine for 1 day [41] and parthenolide for 3 days [10] also led to the appearance of a large number of vesicles inside the flagellar pocket, suggesting a process of exacerbated protein production by cells as they attempt to survive.

Other studies indicated that the plasma membrane of human promyelocytic leukemic HL-60 cells appears to be one of the targets of parthenolide because its integrity is lost very early during cell death, reflected by atypical apoptosis and primary necrosis (i.e., lysis of the membrane) [42].

The lipid spin probe 5-DSA was incorporated into the plasmatic membrane of Leishmania in the usual way, and the EPR spectra obtained were typical for cell membranes. Interestingly, the spectra of the Leishmania membrane were very similar to those for the same spin label in erythrocyte membranes [43]. The erythrocyte membrane of spin-labeled lipids has been well characterized by EPR spectroscopy and is considered to have certain rigidity, particularly because of its high content of protein and cholesterol. The presence of sesquiterpene parthenolide significantly increased the rigidity of the membrane of Leishmania when applied to the cell suspension at a ratio of $3 \times 10^{9}$ parthenolide molecules/cell. Parthenolide also showed dose-dependent anti-Leishmania activity against the amastigote form. The $\mathrm{IC}_{50}$ was $1.3 \mu \mathrm{M}$ parthenolide/ $\mathrm{ml}$ for a cell concentration of $1 \times 10^{6} \mathrm{cell} / \mathrm{ml}$. Therefore, the effect of parthenolide against the amastigote forms of Leishmania was observed at a ratio of $7.8 \times 10^{8}$ parthenolide molecules/cell. The greatest change in membrane fluidity was observed at a concentration 3.8-fold higher than for growth inhibition. Membrane stiffness, assessed by EPR spectroscopy of the spin label, has been associated with lipid peroxidation $[44,45]$. A detailed study of the interaction between parthenolide and membranes and their role as a pro-oxidant in simpler systems is necessary to determine whether the membrane rigidity observed here was attributable to lipid peroxidation.

\section{Conclusions}

Our results indicated that the antileishmanial action of parthenolide is associated with autophagic vacuole appearance, membrane stiffness, the loss of membrane integrity, and mitochondrial dysfunction. These results indicate that parthenolide induced amastigote cell death by autophagy, but other mechanisms of cell death cannot be dismissed, such as apoptosis and necrosis. Considering the limited repertoire of existing antileishmanial compounds, continuously developing new leishmanicidal compounds is essential. In the ongoing search for the best antileishmanial compounds, products derived from plants are gaining ground. The isolation and purification of the active components of medicinal plants has been one the greatest advances. Additionally, delineation of the biochemical mechanisms involved in mediating effect of these compounds would help develop new chemotherapeutic approaches.

\section{Methods \\ Drugs}

Parthenolide (minimum 90\%) was purchased from SigmaAldrich (Steinheim, Germany). Amphotericin B (Cristália, Produtos Químicos Farmacêuticos Ltda, Itapira, SP, Brazil) was used as a positive control. In all of the tests, $0.05 \%$ dimethyl sulfoxide (DMSO; Sigma, St. Louis, MO, USA) was used to dissolve the highest dose of the compounds and had no effect on the parasites' proliferation or morphology.

\section{Axenic amastigotes}

Promastigotes of the Leishmania species differentiate to amastigotes with the combination of low $\mathrm{pH}$ and high temperature [46]. The WHOM/BR/75/Josefa strain of Leishmania amazonensis, isolated by C.A. Cuba-Cuba (University of Brasília, Brasília, Distrito Federal, Brazil) from a human case of diffuse cutaneous leishmaniasis, was used in the present study. Axenic amastigote cultures 
were obtained by the in vitro differentiation of promastigotes from the stationary phase in $25 \mathrm{~cm}^{2}$ tissue culture flasks by progressive temperature increase and $\mathrm{pH}$ decrease [47]. The cultures were maintained at $32^{\circ} \mathrm{C}$ in Schneider's insect medium (Sigma, St. Louis, MO, USA), pH 4.6, with $20 \%$ fetal bovine serum through weekly serial sub-culturing for further studies.

\section{Antiproliferative effect}

For the parasite growth inhibition assays, L. amazonensis axenic amastigotes were harvested during the exponential phase of growth, and $10^{6}$ cells were added to each well of a 24-well plate and treated with different concentrations of parthenolide and amphotericin B. Medium alone and 0.05\% DMSO were used as negative controls. For each treatment, the parasites were observed and counted daily using a Neubauer chamber with an optical microscope. Each experiment was performed in duplicate and twice on different occasions. The antiproliferative effect (percentage of growth inhibition) was evaluated with 5 day treatment, and the data are expressed as the mean \pm standard error of the mean (Microsoft Excel). The corresponding 50\% and $90 \%$ inhibitory concentrations $\left(\mathrm{IC}_{50}\right.$ and $\left.\mathrm{IC}_{90}\right)$ were determined from the concentration-response curves (Excel software). Data were compared via one-way analysis of variance (ANOVA) followed by Tukey's multiple range test for statistically significant differences at $\mathrm{p}<0.05$.

\section{Activity of parthenolide in infection of murine macrophages}

The effect of parthenolide on L. amazonensis-infected mouse peritoneal macrophages was evaluated. The experimental protocol was approved by the Animal Ethics Committee of the Universidade Estadual de Maringá (no. 013/ 2010). BALB/c mice resident peritoneal cells were harvested in phosphate-buffered saline (PBS; $0.01 \mathrm{M}, \mathrm{pH} 7.2$ ) and centrifuged, and the sediment was resuspended in RPMI 1640 medium supplemented with $10 \%$ fetal bovine serum. Cells $\left(1 \times 10^{5}\right)$ were seeded on $13-\mathrm{mm}$ coverslips in 24-well plates and incubated at $37^{\circ} \mathrm{C}$ in a $5 \% \mathrm{CO}_{2}$ atmosphere. After $15 \mathrm{~h}$, macrophages were infected with promastigotes at a 10:1 parasite:cell ratio and incubated again for $6 \mathrm{~h}$. The remaining noninternalized parasites were removed. The infected host cells were treated with parthenolide at concentrations of 4.0, 3.2, 2.4, and 1.6 $\mu \mathrm{M}$. After $24 \mathrm{~h}$, the coverslips were washed with PBS, fixed in methanol, stained with Giemsa, mounted in Entellan (Merck), and examined under an optical microscope. The rate of cell infection and number of amastigotes per cell were evaluated by counting 200 random cells in duplicate cultures in at least two independent experiments. The survival index was calculated by multiplying the percentage of infected macrophages and mean number of internalized parasites per macrophage. Data were compared via one- way analysis of variance (ANOVA) followed by Tukey's multiple range test for statistically significant differences at $\mathrm{p}<0.05$.

\section{Genotoxicity study}

To assess the toxicity of parthenolide in mice, a micronucleus test was conducted in groups of five male and five female Swiss albino mice (Mus musculus) that weighed approximately $42 \mathrm{~g}$. The animals were obtained from the Central Animal House of the Universidade Estadual de Maringá, Paraná, Brazil. They were housed in plastic cages at $22 \pm 1^{\circ} \mathrm{C}$ and $55 \pm 10 \%$ humidity, with a $12 \mathrm{~h} / 12 \mathrm{~h}$ light/ dark cycle and free access to water and food (Nuvilab Cr1). The study was conducted according to experimental standards approved by the Animal Ethics Committee of the Universidade Estadual de Maringá (protocol no. 013/2010).

The animals received $3.75 \mathrm{mg}$ parthenolide $/ \mathrm{kg}$ body weight suspended in $10 \%$ DMSO by oral gavage. The negative control was a vehicle group, and the positive control was a group that received $40 \mathrm{mg}$ cyclophosphamide/ $\mathrm{kg}$ body weight. The mice were examined regularly for mortality and clinical signs of toxicity until sacrifice by carbon dioxide asphyxiation, which occurred $24 \mathrm{~h}$ after treatment. Both femurs were dissected, and bone marrow was flushed with fetal calf serum. After centrifugation for $5 \mathrm{~min}$ at $2,000 \times g, 10 \mu \mathrm{l}$ of the sediment was smeared on glass slides and air-dried. The smears were fixed with absolute methanol for $5 \mathrm{~min}$ and stained with MayGrunwald-Giemsa to detect micronucleated polychromatic erythrocytes (MNPCE). The number of micronucleated cells was counted in 2,000 reticulocytes per animal using an Olympus BH-2 microscope at 1,000× magnification [26]. The statistical analyses were made with a oneway analysis of variance (ANOVA) followed by Dunnet test. Differences were considered significant at $\mathrm{p}$ value of less than 0.05 .

\section{Scanning and transmission electron microscopy}

After treatment with the $\mathrm{IC}_{50}(72 \mathrm{~h})$ of parthenolide, axenic amastigotes were washed in PBS and fixed in $2.5 \%$ glutaraldehyde in $0.1 \mathrm{M}$ sodium cacodylate buffer at $4^{\circ} \mathrm{C}$. For scanning electron microscopy, amastigotes were placed on a specimen support with a poly-L-lysine-coated coverslip and washed in cacodylate buffer. The cells were dehydrated in an increasing ethanol gradient, criticalpoint-dried in $\mathrm{CO}_{2}$, sputter-coated with gold, and observed in a Shimadzu SS-550 SEM scanning electron microscope.

For transmission electron microscopy, amastigote forms were treated with the $\mathrm{IC}_{50}$ of parthenolide and the $\mathrm{IC}_{50}$ of amphotericin B and fixed as described above. The cells were postfixed in a solution that contained $1 \%$ osmium tetroxide, $0.8 \%$ potassium ferrocyanide, and $10 \mathrm{mM}$ calcium chloride in $0.1 \mathrm{M}$ cacodylate buffer, dehydrated in an 
increasing acetone gradient, and embedded in Epon resin. Ultrathin sections were stained with uranyl acetate and lead citrate, and the images were examined in a Zeiss 900 transmission electron microscope.

\section{Fluorescence of monodansylcadaverine during cell death} Axenic amastigotes were treated with $\mathrm{IC}_{50}$ and $\mathrm{IC}_{90}$ equivalents of parthenolide. After $72 \mathrm{~h}$, the cells were washed and resuspended in PBS. To verify the induction of autophagy by parthenolide, the cells were incubated with $0.05 \mathrm{mM}$ monodansylcadaverine (MDC) at $37^{\circ} \mathrm{C}$ for $10 \mathrm{~min}$. After incubation, the cells were washed three times with PBS to remove excess MDC, immediately analyzed by fluorescence microscopy at an excitation wavelength of $360-380 \mathrm{~nm}$ and emission wavelength of $525 \mathrm{~nm}$, and photographed using a charge-coupled-device camera. This study was qualitative.

\section{Flow cytometry}

The antileishmanial activity of parthenolide (20 and $40 \mu \mathrm{M})$ on the integrity of the plasma membrane and mitochondrial membrane potential of axenic amastigotes $\left(5 \times 10^{6}\right.$ cells $\left./ \mathrm{ml}\right)$ was determined after $3 \mathrm{~h}$ treatment. Amphotericin B $(5.0 \mu \mathrm{M})$ and carbonyl cyanide $m$-chlorophenylhydrazone $(200 \mu \mathrm{M})$ were used as positive controls. Untreated amastigotes were used as a negative control. Each flow-cytometric technique was evaluated by repeating each experiment three times to verify reproducibility.

The integrity of the plasma membrane was assessed using $L$. amazonensis amastigotes at an average density of $5 \times 10^{6}$ cells suspended in $500 \mu \mathrm{l}$ PBS and stained with $50 \mu \mathrm{l}$ propidium iodide $(2 \mu \mathrm{g} / \mathrm{ml})$ for $5 \mathrm{~min}$ at room temperature.

To measure mitochondrial membrane potential $\left(\Delta \Psi_{\mathrm{m}}\right)$, $1 \mathrm{ml}$ of saline that contained $1 \times 10^{6}$ of treated amastigotes was mixed with $1 \mu \mathrm{l}$ rhodamine $123(5 \mathrm{mg} / \mathrm{mL})$ for $15 \mathrm{~min}$ at $37^{\circ} \mathrm{C}$. The cells were washed, resuspended in PBS, and incubated at the same temperature for $30 \mathrm{~min}$.

A total of 10,000 events were analyzed per sample using a FACSCalibur cytometer, and numeric data were processed with Cellquest software (both from Becton Dickinson). Propidium iodide and rhodamine 123 are excited with a $480 \mathrm{~nm}$ argon ion laser, and fluorescence emission occurs at 560-580 nm and 515-530 nm, respectively.

\section{Electron paramagnetic resonance spectroscopy}

Spin-label 5-doxyl stearic acid (5-DSA), with a nitroxide radical moiety (doxyl) in the fifth carbon atom of the acyl chain, was purchased from Sigma (St. Louis, MO, USA). A small aliquot $(3 \mu \mathrm{l})$ of stock solution of the spin label in ethanol $(2 \mathrm{mg} / \mathrm{ml})$ was transferred to a glass tube. After the solvent evaporated, approximately $2.4 \times 10^{8}$ cells of Leishmania suspended in $40 \mu \mathrm{lBS}$ was added to the film of the spin label with gentle agitation. In a second tube, $6 \mu \mathrm{l}$ of a stock solution of parthenolide in chloroform (201 mM) was added. After evaporation of the solvent, the first spin-labeled cell suspension was placed on the parthenolide film and gently agitated. The cells were then introduced into a $1 \mathrm{~mm}$ inner diameter capillary column for electron paramagnetic resonance (EPR) measurements, which was sealed by flame. Samples were also prepared that contained double and triple the concentrations of parthenolide used in the first sample (using 12 and $18 \mu \mathrm{l}$ of the solution of parthenolide in chloroform, respectively).

Electron paramagnetic resonance spectroscopy was performed with a Bruker ESP 300 spectrometer (Rheinstetten, Germany) equipped with an ER 4102 ST resonator. The instrument settings were the following: microwave power, $10 \mathrm{~mW}$; modulation frequency, $100 \mathrm{KHz}$; modulation amplitude, 1.0 G. Electron paramagnetic resonance spectra simulations were performed using the NLLS program developed by Budil and coworkers [48]. In the spectral calculations, the NLLS program includes the magnetic g- and A-tensors and rotational diffusion tensor, $R$, which are expressed in a system of Cartesian axes fixed in the spinlabeled molecule. To reduce the number of parameters in the fittings and simplify the simulation, the average rotational diffusion rate, $R_{b a r}$ was calculated by the fitting program using the relationship $R_{b a r}=\left(R_{p e r}^{2} \cdot R_{p a r}\right)^{1 / 3}$, in which $R_{p e r}$ is the perpendicular component of the rotational diffusion, and $R_{p a r}$ is the parallel component of the rotational diffusion. $R_{b a r}$ was converted to the parameter rotational correlation time, $\tau_{c}$, following the relationship $\tau_{c}=1 / 6 R_{b a r}$. Similar to previous studies $[49,50]$, the magnetic parameters were determined based on a global analysis of the overall spectra obtained in this work, and all of the EPR spectra were simulated using the same predetermined parameters. In this work, the spectra were simulated with a model of two spectral components.

\section{Competing interests}

The authors declare that they have no competing interests.

\section{Authors' contributions}

TST conceived and designed the study, carried out all the experimental studies and drafted the manuscript. TUN participated in the design of the study. AA assisted with EPR spectra and helped to draft the manuscript. CVN conceived of the study, and participated in its design and coordination and helped to draft the manuscript. All authors read and approved the final manuscript.

\section{Acknowledgements}

This study was supported by grants from Conselho Nacional de Desenvolvimento Científico e Tecnológico (CNPq), Coordenação de Aperfeiçoamento de Pessoal de Nivel Superior (CAPES), Financiadora de Estudos e Projetos (FINEP), Complexo de Central de Apoio a Pesquisa (COMCAP) - Universidade Estadual de Maringá, and Programa de Pós-graduação em Ciências Farmacêuticas - Universidade Estadual de Maringá. 


\section{Author details}

'Programa de Pós-Graduação em Ciências Farmacêuticas, Universidade Estadual de Maringá, Av. Colombo 5790, 87020-900 Maringá, Paraná, Brazil. ${ }^{2}$ Instituto de Física, Universidade Federal de Goiás, Campus II, CEP 74001-970 Goiânia, Goiás, Brazil.

Received: 24 January 2014 Accepted: 21 May 2014

Published: 10 June 2014

\section{References}

1. WHO: Leishmaniasis: magnitude of the problem. World Health Org 2013, [http://www.who.int/leishmaniasis/burden/magnitude/burden_magnitude/en/]

2. Fernández-Guerrero $M L$, Robles $P$, Rivas $P$, Mójer F, Muñíz G, Górgolas M: Visceral leishmaniasis in immunocompromised patients with and without AIDS: a comparison of clinical features and prognosis. Acta Trop 2004, 90:11-16.

3. Carnaúba-Jr D, Konishi CT, Petri V, Martinez ICP, Shimizu L, Pereira-Chioccola VL: Atypical disseminated leishmaniasis similar to post-kala-azar dermal leishmaniasis in a Brazilian AIDS patient infected with Leishmania (Leishmania) infantum chagasi: a case report. Int J Infect Dis 2009, 13:504-507

4. Barral A, Pedral-Sampaio D, Grimaldi Júnior G, Momen H, McMahon-Pratt D, Ribeiro De Jesus A, Almeida R, Badaro R, Barral-Netto M, Carvalho EM, Johnson Júnior WD: Leishmaniasis in Bahia, Brazil: evidence that Leishmania amazonensis produces a wide spectrum of clinical disease. Am J Trop Med Hyg 1991, 44:536-546.

5. Oliveira JPC, Fernandes F, Cruz AK, Trombela V, Monteiro E, Camargo AA, Barral A, Oliveira Cl: Genetic diversity of Leishmania amazonensis strains isolated in northeastern Brazil as revealed by DNA sequencing, PCRbased analyses and molecular karyotyping. Kinetoplastid Biol Dis 2007 doi:10.1186/1475-9292-6-5.

6. Croft SL, Coombs GH: Leishmaniasis - current chemotherapy and recent advances in the search for novel drugs. Trends Parasitol 2003, 19:502-508.

7. Tiuman TS, Santos AO, Ueda-Nakamura T, Dias Filho BP, Nakamura CV: Recent advances in leishmaniasis treatment. Int J Infect Dis 2011 15:e525-e532.

8. Croft SL, Sundar S, Fairlamb AH: Drug resistance in leishmaniasis. Clin Microbiol Rev 2006, 19:111-126.

9. Natera S, Machuca C, Padrón-Nieves M, Romero A, Díaz E, Ponte-Sucre A: Leishmania spp.: proficiency of drug-resistant parasites. Int J Antimicrob Agents 2007, 29:637-642

10. Tiuman TS, Ueda-Nakamura T, Cortez DAG, Dias Filho BP, Morgado-Díaz JA De Souza W, Nakamura CV: Antileishmanial activity of parthenolide, a sesquiterpene lactone isolated from Tanacetum parthenium. Antimicrob Agents Chemother 2005, 49:176-182

11. Tiuman TS, Ueda-Nakamura T, Dias-Filho BP, Cortez DAG, Morgado-Díaz JA Nakamura CV: Morphologic and ultrastructural alterations in Leishmania amazonensis induced by 4a,5ß-epoxy-germacra-1(10),11(13)-dien-12,6a-olide Acta Protozool 2007, 46:349-355.

12. Linsinger $\mathrm{G}$, Wilhelm $\mathrm{S}$, Wagner $\mathrm{H}$, Häcker $\mathrm{G}$ : Uncouplers of oxidative phosphorylation can enhance a Fas death signal. Mol Cell Biol 1999, 19:3299-3311.

13. Jost PC, Griffith $\mathrm{OH}$, Capaldi RA, Vanderkooi G: Evidence for boundary lipid in membranes. Proc Natl Acad Sci U S A 1973, 70:480-484.

14. Rotureau B: Are new world leishmaniases becoming anthroponoses? Med Hypotheses 2006, 67:1235-1241.

15. WHO: Urbanization: an increasing risk factor for leishmaniasis. WklyEpidemiol Rec 2002, 77:365-370.

16. Polonio T, Efferth T: Leishmaniasis: drug resistance and natural products (review). Int J Mol Med 2008, 22:277-286.

17. Sereno $D$, Lemesre $\mathrm{J}$ : Axenically cultured amastigote forms as an in vitro model for investigation of antileishmanial agents. Antimicrob Agents Chemother 1997, 41:972-976.

18. Sen $\mathrm{R}$, Chatterjee M: Plant derived therapeutics for the treatment of leishmaniasis. Phytomedicine 2011, 18:1056-1059.

19. Kayser O, Kiderlen AF, Croft SL: Natural products as antiparasitic drugs. Parasitol Res 2003, 90:S55-S62.

20. Sikkema J, De Bont JAM, Poolman B: Mechanisms of membrane toxicity of hydrocarbons. Microbiol Rev 1995, 59:201-222

21. Fumarola $L$, Spinelli $R$, Brandonisio $O$ : In vitro assays for evaluation of drug activity against Leishmania spp. Res Microbiol 2004, 155:224-230.
22. Sereno D, Cordeiro Da Silva A, Mathieu-Daude F, Ouaissi A: Advances and perspectives in leishmania cell based drug-screening procedures. Parasitol Int 2007, 56:3-7.

23. Weniger B, Robledo S, Arango GJ, Deharo E, Aragón R, Muñoz V, Callapa J, Lobstein A, Anton R: Antiprotozoal activities of Colombian plants. J Ethnopharmacol 2001, 78:193-200.

24. Weniger B, Vonthron-Sénécheau C, Kaiser M, Brun R, Anton R: Comparative antiplasmodial, leishmanicidal and antitrypanosomal activities of several biflavonoids. Phytomedicine 2006, 13:176-180.

25. Winter MJ, Ellis LCJ, Hutchinson TH: Formation of micronuclei in erythrocytes of the fathead minnow (Pimephales promelas) after acute treatment with mitomycin C or cyclophosphamide. Mutat Res 2007, 629:89-99.

26. Costa MA, Ishida K, Kaplum V, Koslyk ED, de Mello JC, Ueda-Nakamura T, Dias Filho BP, Nakamura CV: Safety evaluation of proanthocyanidin polymer-rich fraction obtained from stem bark of Stryphnodendron adstringens (BARBATIMAO) for use as a pharmacological agent. Regul Toxicol Pharmacol 2010, 58:330-335.

27. Hayashi M, MacGregor JT, Gatehouse DG, Adler I, Blakey DH, Dertinger SD, Krishna G, Morita T, Russo A, Sutou S: In vivo rodent erythrocyte micronucleus assay. II. Some aspects of protocol design including repeated treatments, integration with toxicity testing, and automated scoring. Environ Mol Mutagen 2000, 35:234-252.

28. Edinger AL, Thompson CB: Death by design: apoptosis, necrosis and autophagy. Curr Opin Cell Biol 2004, 16:663-669.

29. Klionsky DJ, Abeliovich H, Agostinis P, Agrawal DK, Aliev G, Askew DS, Baba M, Baehrecke EH, Bahr BA, Ballabio A, Bamber BA, Bassham DC, Bergamini E, Bi X, Biard-Piechaczyk M, Blum JS, Bredesen DE, Brodsky JL, Brumell JH, Brunk UT, Bursch W, Camougrand N, Cebollero E, Cecconi F, Chen Y, Chin LS, Choi A, Chu CT, Chung J, Clarke PG, et al: Guidelines for the use and interpretation of assays for monitoring autophagy in higher eukaryotes. Autophagy 2008, 4:151-175.

30. Biederbick A, Kern HF, Elsässer HP: Monodansylcadaverine (MDC) is a specific in vivo marker for autophagic vacuoles. Eur J Cell Biol 1995, 66:3-14.

31. Mizushima N: Methods for monitoring autophagy. Int J Biochem Cell Biol 2004, 36:2491-2502.

32. Munafó DB, Colombo Ml: A novel assay to study autophagy: regulation of autophagosome vacuole size by amino acid deprivation. J Cell Sci 2001 114:3619-3629.

33. Bera A, Singh S, Nagaraj R, Vaidya T: Induction of autophagic cell death in Leishmania donovani by antimicrobial peptides. Mol Biochem Parasitol 2003, 127:23-35.

34. Cohen BE: Amphotericin B membrane action: role for two types of ion channels in eliciting cell survival and lethal effects. J Membr Biol 2010, 238:1-20.

35. Di Giorgio C, Faraut-Gambarelli F, Imbert A, Minodier P, Gasquet M, Dumon H: Flow cytometric assessment of amphotericin B susceptibility in Leishmania infantum isolates from patients with visceral leishmaniasis. J Antimicrob Chemother 1999, 44:71-76.

36. Dengler WA, Schulte J, Berger DP, Mertelsmann R, Fiebig HH: Development of a propidium iodide fluorescence assay for proliferation and cytotoxicity assays. Anticancer Drugs 1995, 6:522-532.

37. Riccardi C, Nicoletti I: Analysis of apoptosis by propidium iodide staining and flow cytometry. Nat Protoc 2006, 1:1458-1461.

38. Scaduto RC Jr, Grotyohann LW: Measurement of mitochondrial membrane potential using fluorescent rhidanmine derivatives. Biophys J 1999 76:469-477.

39. Menna-Barreto RFS, Goncalves RLS, Costa EM, Silva RSF, Pinto AV, Oliveira MF, Castro SL: The effects on Trypanosoma cruzi of novel synthetic naphthoquinones are mediated by mitochondrial dysfunction. Free Radic Biol Med 2009, 47:644-653

40. Gottlieb E, Armour SM, Harris MH, Thompson CB: Mitochondrial membrane potential regulates matrix configuration and cytochrome $c$ release during apoptosis. Cell Death Differ 2003, 10:709-717.

41. Santa-Rita RM, Henriques-Pons A, Barbosa HS, Castro SL: Effect of the lysophospholipid analogues edelfosine, ilmofosine and miltefosine against Leishmania amazonensis. J Antimicrob Chemother 2004, 54:704-710.

42. Pozarowski P, Halicka DH, Darzykiewicz Z: NF-kB inhibitor sesquiterpene parthenolide induces concurrently atypical apoptosis and cell necrosis: difficulties in identification of dead cells in such cultures. Cytometry 2003, 54A:118-124. 
43. Alonso A, Meirelles NC, Tabak M: Effect of hydration upon the fluidity of intercellular membranes of stratum corneum: an EPR study. Biochim Biophys Acta 1995, 1237:6-15

44. Alonso A, Queiroz CS, Magalhães AC: Chilling stress leads to increased cell membrane rigidity in roots of coffee (Coffea arabica L.) seedlings. Biochim Biophys Acta 1997, 1323:75-84.

45. Nepomuceno MF, Alonso A, Pereira-da-Silva L, Tabak M: Inhibitory effect of dipyridamole and its derivatives on lipid peroxidation in mitochondria. Free Radic Biol Med 1997, 23:1046-1054.

46. Zilberstein $\mathrm{D}$ : The role of $\mathrm{pH}$ and temperature in the development of Leishmania parasites. Annu Rev Microbiol 1994, 48:449-470

47. Ueda-Nakamura T, Attias M, Souza W: Megasome biogenesis in Leishmania amazonensis: a morphometric and cytochemical study. Parasitol Res 2001, 87:89-97.

48. Budil DE, Lee $\mathrm{S}$, Saxena S, Freed JH: Nonlinear-least-squares analysis of slow-motional EPR spectra in one and two dimensions using a modified Levenberg-Marquardt algorithm. J Magn Reson 1996, A120:155-189.

49. Dos Anjos JLV, Neto DD, Alonso A: Effects of ethanol/L-menthol on the dynamics and partitioning of spin-labeled lipids in the stratum corneum. Eur J Pharm Biopharm 2007, 67:406-412.

50. Dos Anjos JLV, Alonso A: Terpenes increase the partitioning and molecular dynamics of an amphipathic spin label in stratum corneum membranes. Int J Pharm 2008, 350:103-112.

doi:10.1186/1471-2180-14-152

Cite this article as: Tiuman et al.: Cell death in amastigote forms of Leishmania amazonensis induced by parthenolide. BMC Microbiology 2014 14:152.

\section{Submit your next manuscript to BioMed Central and take full advantage of:}

- Convenient online submission

- Thorough peer review

- No space constraints or color figure charges

- Immediate publication on acceptance

- Inclusion in PubMed, CAS, Scopus and Google Scholar

- Research which is freely available for redistribution 